\title{
Julie Barnsley: la empatía kinestésica en la rebeldía del cuerpo y su performatividad
}

\author{
Julie Barnsley: kinesthetic empathy in the body in states of \\ rebellion and his performativity
}

LEYSON ORLANDO PONCE FLORES

\begin{abstract}
Resumen: El imaginario sobre la rebeldía del cuerpo ha sido un referente indiscutible en los estudios dramatúrgicos y prácticas performativas abocados a esta novedosa perspectiva estética. En el ámbito concreto de la danza contemporánea venezolana, la noción de rebeldía elaborada por la británica Julie Barnsley ocupa un puesto privilegiado como herramienta de comprensión y exégesis en los análisis semióticos y ontológicos del cuerpo y su movimiento en tanto organicidad y nueva sensibilidad. Ante la vigencia de su propuesta, resulta preciso insistir en la particularidad de su nueva consciencia de cuerpo frente a otros usos e interpretaciones del proceder performativo. En tal sentido, este artículo tratará de enfatizar en la especificidad de sus ideas sobre el fenómeno, a través de un recorrido teórico en el proceso kinestésico y recepción de esa rebeldía del cuerpo planteada por esta coreógrafa y directora escénica en el contexto de la danza contemporánea en Venezuela.

Palabras clave: Rebeldía del cuerpo, danza contemporánea, semiótica del cuerpo, empatía kinestésica.
\end{abstract}

\begin{abstract}
The body in states of rebellion, has been, (for those who investigate around this new perspective in aesthetics), an indisputable reference in dramaturgical studies and performance art practices. In the concrete world of the Venezuelan Contemporary Dance movement, the notion of rebellion elaborated by the british choreographer julie Barnsley occupies a privileged place, as a tool for understanding and interpreting semiotic and ontological analyses based on the body and it's movements, as it proposes a new visión with respect to the organicity and sensibility of the body. In front of the importance of this proposal it results pertinent to insist in the unique nature of this new consciousness of the body, in relation to other uses and interpretations of it in performance art. In this way, this article intends to emphasise the specificity of her ideas around this phenomenen, by means of a theoretical investigation of the particular kinesthetic process and rebellion established by this artistic director and choreographer, in the context of the Venezuelan Contemporary Dance scene.
\end{abstract}

Keywords: Body in Rebellion, Contemporary Dance, Semiology of the Body, Kinesthetic Empathy.

Fecha de recepción: 15/05/2016. Fecha de aceptación: 27/07/2016.

* Universidad Nacional Experimental de las Artes (Venezuela). Director de Desarrollo Profesoral (2008-2014). Docente de la unidad curricular Composición Coreográfica desde 1999. Líneas de investigación: La estética de la performatividad, Las empatías kinestésicas, Composición coreográfica y performatividad. Publicaciones: Del Cuerpo Teatralizado en la Posmodernidad. Perspectiva estética de la danza posmoderna: una experiencia para vivir la metáfora de las imágenes. En diálogo con Pina Bausch y George Dídi-Huberman. Y El signo hegeliano en la danza expresionista alemana, dialéctica de una premonición en: Kurt Jooss y Der Grüne Tisch (1932). Contacto: leysonponce@yahoo.com 
El presente ensayo lo centraremos en lo que la coreógrafa británica Julie Barnsley residenciada en Venezuela llama territorio de la rebeldía del cuerpo en la danza contemporánea. Ello abre posibles recorridos; entre los cuales el más importante, abordar la danza desde su núcleo expresivo para validarse como creación en al arte. Quizás en esa relación, la posibilidad de referenciar al movimiento nos conduce al proceso coreográfico como exposición de una reivindicación del cuerpo en tanto su actualidad performativa en nuestra cultura mediática. Por esto, la danza rivaliza con categorías intelectuales o artísticas en nuestra cultura contemporánea, Laurence Louppe dice: "En las últimas décadas se ha convertido en una de las más ejemplares fuerzas de integración y expresión de la consciencia actual"'.

Más allá del consumo efímero de su representación o exhibición como dijera Benjamin; nuestro propósito es examinar (y ello implicará una identificación y un reconocimiento) el campo coreográfico, sus modos, sus elementos escénicos, como espacio liminal de una performatividad donde el movimiento nos conduce y donde interesa reconocer y examinar el umbral de ese desplazamiento a través de sensaciones y diversas percepciones propia de los imaginarios que la performatividad abre como nuevas sensibilidades en el espectador; permitiendo así, la discusión del complejo mundo de la danza contemporánea desde planteamientos teóricos que, a la par de planteamientos prácticos, Barnsley moviliza como experiencia indivisible.

En este sentido, la danza no expresa a la realidad tal cual es, sino que la distorsiona para reconocerla en su cara oculta. La danza desdice la realidad porque la atraviesa con el cuerpo horizontal y verticalmente para mostrarla en su lateralidad. De este modo, no hay relaciones directas sino dialécticas, y en esa fractura, Julie Barnsley en Venezuela abre la posibilidad de reconocer su cualidad estética y su fundamentación artística desde su instrumento más valioso: el cuerpo en estado de rebeldía.

La rebeldía del cuerpo es un estado de conocimiento (pensamiento) y por ende de significados (imaginación). La incursión de Barnsley en la investigación coreográfica, la realizó sin perder su esencia de intérprete; con esto queremos puntualizar, que los límites de ambas instancias (interpretación y creación) no representaran connotaciones distintas frente a la recepción del espectador quién percibirá una danza con una marcada libertad de movimientos sujetos a impulsos oscilantes que hacen de la obra una imposible repetición y por ello un vaivén entre lo que se piensa y lo que se imagina. De esta manera el intérprete-creador es fundamental en esta danza, siendo la formación y la coreografía la conjugación de una compleja red que oscila entre el conocimiento y sus significados para generar el sentido de esa condición rebelde de cuerpo y sus correspondientes implicaciones.

Desde esta perspectiva, la teoría de la liminalidad de Turner ${ }^{2}$ sobre la base del análisis del funcionamiento teatral cobra sentido en tanto, el umbral de tensiones entre interpretar y crear es un umbral de indefinición en donde el cuerpo técnico y el cuerpo creativo interactúan. En palabras de Cornago y a propósito de este concepto de Turner comenta que:

1 LOUPPE, Laurence (2011): Poética de la danza contemporánea, (trad. A. Fernández), Ediciones Universidad de Salamanca, Salamanca, p. 16.

2 Cfr., TURNER, Victor (1982): From Ritual to Theatre. The human seriousness of play, Performing Arts Journal Publications, New York. 
La liminalidad puede ser entendida dentro de una concepción global de la cultura en tanto que campo de fuerzas en transformación; se trata de un fenómeno que introduce los espacios y funciones en un proceso de constante redefinición, en la busquedad de otros modos de construcción de significados, experimentando con nuevos canales de percepción. ${ }^{3}$

En ese orden de ideas, Cornago a propósito de la teatralidad nos plantea también la diferencia entre camino y recorrido ${ }^{4}$, la cual trasladamos a nuestro estudio entendiendo que la interpretación para Barnsley, implica un camino con una clara posición entre lo que significa iniciar en un punto y terminar en otro; y la creación sin embargo, implica un recorrido, donde no interesa inicio ni final, sino el propio trayecto que Barnsley llama proceso. Ambas instancias, camino y recorrido conforman una performatividad en movimiento en su proyecto coreográfico llamado Aktion Kolectiva; en donde concretamente podemos observar que la coreografía y sus cuerpos como territorios rebeldes representan el devenir de un movimiento en tanto instancia técnica/creativa errático, efímero, azaroso, pero portentosamente sabio: intentando vivenciar una nueva experiencia de cuerpo y danza en sintonía con las fuerzas irracionales de la naturaleza para revelar de ella otras sensibilidades oprimidas. Barnsley danza así, bajo el signo de la incertidumbre; para ella, la rebeldía es un nuevo espacio autorreferencial. En sus palabras:

A pesar de las múltiples interpretaciones ofrecidas en los inicios de la historia occidental para explicar los fenómenos del cuerpo y de la naturaleza, vemos cómo la civilización avanza adoptando más bien ideologías en donde se discriminan las expresiones irracionales e intangibles de la naturaleza, estableciendo así una posición de distanciamiento y confrontación con ella en vez de una posible integración y coordinación. 5

$\mathrm{Al}$ alejarse del ejercicio tradicional de la coreografía, Barnsley irrumpe la estética de la danza contemporánea en tanto trasciende la mímesis del movimiento, por psíquica del movimiento. El cuerpo en estado de rebeldía supone un rompimiento con los códigos heredados de la danza clásica y moderna, por ello, los cuerpos oscilan entre la fuerza natural de sus impulsos energéticos intuitivos con los racionales. Establece en ese punto una forma de inteligencia de cuerpo desprovista de pensamientos estructurados sobre la fenomenología de la danza; Barnsley intuye y construye su obra y desde esa estrategia opuesta al conocimiento tradicional, su elaboración reacciona a la fuerza orgánica del gesto que emana de un imaginario y una memoria afectiva que va a centrar en el bajo vientre como receptáculo de una nueva epistemología. va a la par del propio análisis teórico desarrollándose sincrónicamente con la práctica y transformándose según las necesidades kinestésicas de cada obra. Entonces, no constreñiremos su significado asignándole alguna teoría o practica determinada; estas aparecerán para contribuir al análisis de una experiencia que se encuentra en movimiento permanente y por ello consideramos que desde la misma práctica de la danza, posibles respuestas podremos desentrañar.

3 CORNAGO , Óscar (2003): Pensar la teatralidad. Miguel Romero Esteo y las estéticas de la modernidad, Editorial Fundamentos, Madrid, p. 24.

4 Ibídem., pp. 17-19.

5 BARNSLEY, Julie (2013): El cuerpo como territorio de la rebeldía, 2a. ed., UNEARTE, Caracas, p. 34. 
Barnsley y su danza implican un desafío porque no baila lo estandarizado. Parte de la premisa que los contextos históricos y sus intereses ideológicos-políticos han afectado la naturaleza humana y por ende su capacidad de sentir, pensar y de desarrollo hacia una libertad creativa plena del movimiento. Allí una primera característica de su rebeldía. En el recorrido de su experiencia si categorizamos los elementos constitutivos de su performatividad, como un primer problema, nos toparemos que al descodificar los tradicionales signos de la danza productos de la escisión cultural de mente y cuerpo y de un sistema intrincado del poder patriarcal heredado culturalmente en nuestras sociedades; Barnsley va arremeter contra la noción que sobre lo bello y verdadero ha hecho tanto daño en la noción del intérprete-creador, pero su arremetimiento no es rebeldía sin causa, sino la necesidad de construir y agitar esas nociones para establecer un territorio de transformaciones donde se replantee el ejercicio coreográfico como un asunto para reflexionar sobre las posibilidades de conformar un arte que más allá de lo espectacular, convoque a nuevas reflexiones de cuerpo y mente, haciendo de ésto nuevas prácticas y, por ende, ese recorrido conlleve a nuevas significaciones.

Esta cuestión problemática amerita una breve explicación: la concepción que tiene Barnsley de la danza esta constituida primero por una divergencia como es la de descodificar los signos heredados de la danza moderna y del ballet clásico como el gran "logos de la razón"; y segundo, esa descodificación implica a su vez o la anulación de códigos preestablecidos, o la sustitución por nuevos códigos constituidos por ella como gran "logos de la naturaleza", lo que nos conduce a la esencial pregunta de si tal actividad es una intervención sustitutiva razón-naturaleza, o si por el contrario es una transformación en el terreno fenomenológico del movimiento.

En el mismo orden, nos planteamos otra problemática: el impulso de acercarnos a la obra coreográfica de Barnsley tiene que ver con una necesidad muy distinta a la de desentrañar una estructura coreográfica; nuestra aproximación intenta, en lugar de eso, indagar sobre un sentido de ida y vuelta, los movimientos internos del intérprete y las respectivas consecuencias en lo exterior y viceversa, así como las atmósferas afectivas y los vínculos con la empatía kinestésica y su performatividad; entendida esta performatividad como indica Fischer-Lichte como realización escénica ${ }^{6}$. Se trata de evidenciar la complejidad del proceso coreográfico, tomando en cuenta no sólo las elecciones conscientes de nuestra coreógrafa, sino también aquello que va más allá de los individuos y que se construye en conjunto a través de los horizontes múltiples hacia los que se extienden las líneas de dispersión de la experiencia subjetiva en la danza.

$\mathrm{Su}$ propuesta integradora de diversas disciplinas persiguen una síntesis como unidad creativa, centrada en el reconocimiento de las empatías kinestésicas que examinaremos más adelante y su funcionamiento, en el cómo de su propuesta en tanto, esas empatías responden a consolidar una nueva semántica de la danza si pensamos en semántica en este primer momento de manera muy general como Turner indica: "The relationship of signs and symbols to the thing to which they refer, that is, their referential meaning" , o como Eco emplaza diciendo: "la semiótica no es solamente una teoría, ha de ser también una forma de la praxis"8.

6 FISCHER-LICHTE, Erika (2011): Estética de lo performativo, (trads. Diana González Martín; David Martínez Perucha), Abada Editores, Madrid, p. 58.

7 TURNER, Victor (1982): From Ritual to Theatre, Op.cit., p. 22.

8 ECO, Umberto (1998): Signos, (trad. Francisco Serra), Editorial Labor, Barcelona, p. 20. 
Estas hipótesis sobre los modos del movimiento en codificaciones y des-codificaciones de la danza suponen para nuestra investigación indagar y examinar el complejo tejido establecido por nuestra autora como una actividad estética transformadora desde el propio cuerpo como instrumento. Para Barnsley la relación entre la acción, la interpretación y el sentido de la narratividad del movimiento tiene como esencia examinar planos psíquicos para consolidar el valor perdido del gesto y su potencialidad significativa en el hombre de hoy, haciendo de ello una nueva danza con aroma de vida y cotidianidad, o como bien dice: "De cómo la danza ha transformado mi vida y en cómo la vida ha transformado mi danza"9. Su propuesta supone una abstracción de cuerpo que se integra a otras disciplinas, no como añadido o decorado, sino como parte constitutiva de los signos que responden a la dimensión sintiente del bailarín y de la propia Barnsley y lo que esto implica en la audiencia.

Entendamos que los signos heredados de la danza moderna como formas abstractas del movimiento tienen para ella correspondencia directa con estados expresivos ya configurados, es decir, que han perdido para ella su poder de significación en tanto su repetición ya no establece relación entre el signo, el símbolo y a la relación de referencia como significado de algo; con esto aniquilamos la noción de semántica de Turner; de allí su necesidad por transformarlos y conferirles el nuevo valor y re-significación propios de un entorno que dialoga con sus intérpretes como el lugar de su danza y la codificación de las vivencias resemantizando el movimiento desde las señales naturales y los signos culturales implícitos.

Desde esta perspectiva, el territorio de la rebeldía del cuerpo en Barnsley no es sólo una categoría evocativa ni superficial que dispone sobre las relaciones entre las cosas del mundo de la danza y de la vida para producir coreografías, sino que debemos comprenderla como la intrincada relación que se suscita entre el cuerpo, su movimiento y la danza como discurso de algo que interactúa desde el adentro y el afuera en un dialogo en donde se toma o se deja lo que necesita el intérprete de esa especie de bipolaridad, entre la obra y el espectador: la oscilación kinestésica, o como Barnsley hace saber al trabajar en ese estado de liberación físico-emocional para abrir una nueva sensibilidad en la danza, elaborada en las significaciones de las operaciones de la vida.

Es este orden de ideas, la rebeldía del cuerpo supone nuevas posibilidades discursivas. Barnsley ha trabajado partituras musicales comisionadas especialmente para sus obras. Recurre a su vez a las "nuevas" tecnologías especialmente a partir del año 2000, luego que una nueva dimensión de las comunicaciones se había abierto en la década de los noventa; indagando siempre en las empatías kinestésicas de su performatividad con las nuevas practicas de la comunicación, sometiendo su obra a un proceso de reflexión creativa y llevando a la práctica el traslado de la técnica del cuerpo por la tecnología aplicada a él en sus producciones, donde intercede por ejemplo el video como un mapping coreográfico para determinar otras espacialidades performativas, o como propuesta de iluminación dramática con imágenes o proyectografías haciendo de su danza una investigación también de formatos como observamos en la siguiente figura.

9 BARNSLEY, Julie (2013): Op. cit., p. 13. 


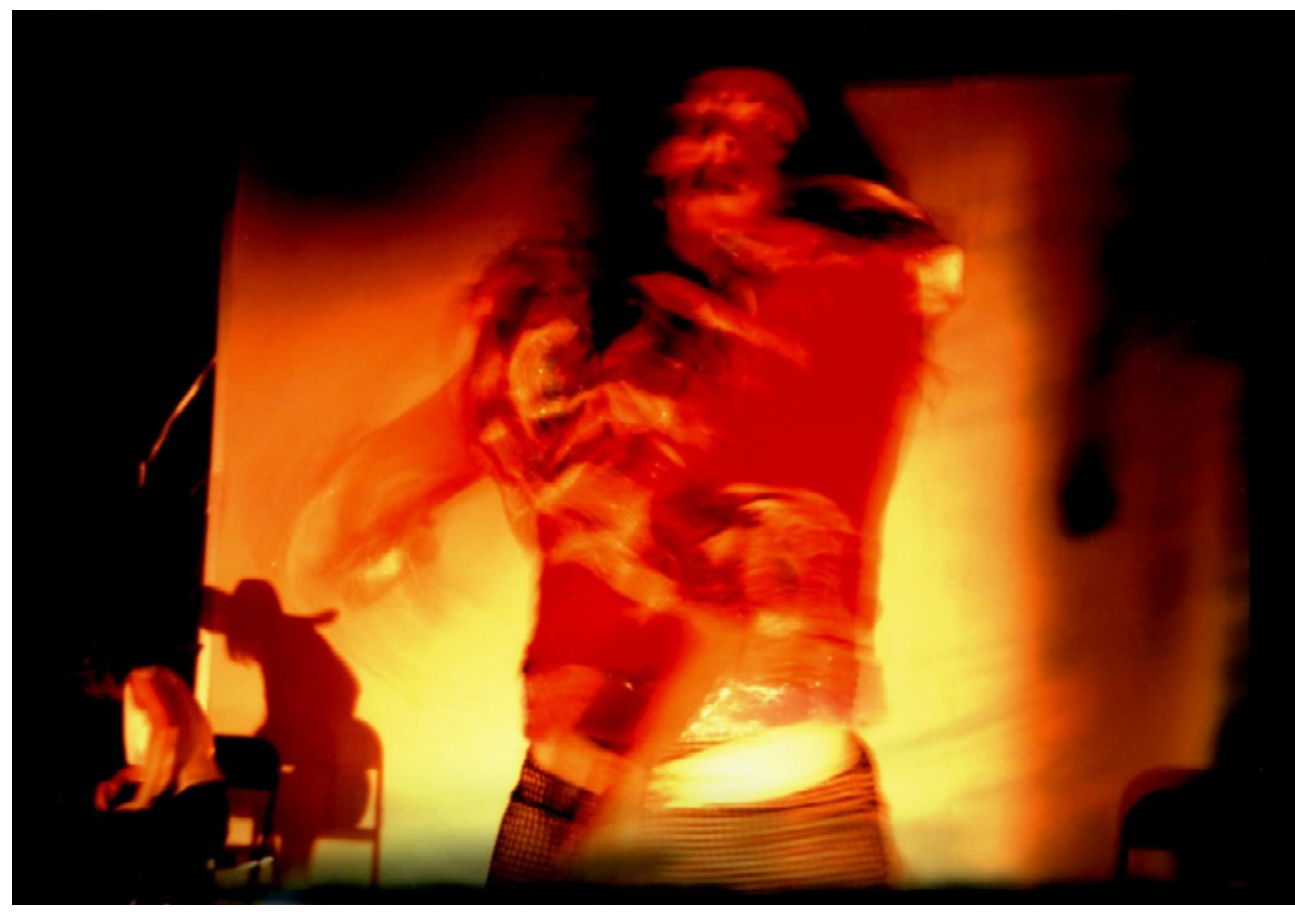

Figura 1: SAHKTI EN ASCENSIÓN O RAINBOW REVISITED. 2006. Dirección coreográfica: Julie Barnsley. Intérpretes: Claudia Capriles I Vanessa Lozano I Julie Barnsley. Videos: Goar Sánchez. Fotografía: Renato Donzelli. Tomado de: http://aktionkolectiva.com/?page_id=1205

De este modo, lo rebelde del cuerpo lo examinamos desde el entendimiento del movimiento y de los impulsos que estructura como tejido dramatúrgico. Impulsos que movilizan su corposfera ${ }^{10}$ en la danza, en cuanto a un sistema relacional de cuerpo, tiempo y espacio y que, por otra parte, en el mejor ejemplo de Molinuevo moviliza su sentido estético ${ }^{11}$ en cuanto al carácter de su experimentación. Será la rebeldía una estética de experimentación hacia una nueva danza que será operativa a las nuevas tecnologías junto a la Neurociencia como un proceso integrador. Ese proceso neuro-dancístico lo desarrolla en la actualidad

10 Comenta José Enrique Finol: "El cuerpo, todo y en todo momento, incluso a su pesar, significa. En sí mismo y en el conjunto de sus relaciones, el cuerpo constituye una suerte de corposfera, (...) la corposfera incluiría no solo los lenguajes corporales sino también sus contextos y las relaciones que se establecen entre aquel y estos; es en el conjunto de esas relaciones dinámicas que el cuerpo crea y actualiza en el mundo donde, finalmente, opera la semiotización”. FINOL, José Enrique (2015): La corpoesfera. Antropo-semiótica de las cartografías del cuerpo, Ediciones CIESPAL, Quito, p. 41.

11 Comenta José Luis Molinuevo:’Una estética del trabajo se puede desarrollar tomando como base dos palabras: experiencia y experimentación. La experiencia obliga a la estética a reconocer que su teoría debería salir de las prácticas, no al revés; la experimentación es su resultado, es decir, la faceta creativa inherente a moverse en ese territorio entre los diversos usos sociales, prácticas de la estética. MOLINUEVO, José Luis (2015): Laocoonte, "Definición, uso, abuso y propuestas estéticas". Revista de Estética y Teoría de las Artes. Vol 2. VOL. № 2. España, pp. 47-56. 
como un estudio multidisciplinario de enseñanza-aprendizaje a través de un módulo universitario que ha llamado Conciencia Exploratoria Corporal en la Universidad Nacional Experimental de las Artes UNEARTE desde 2008.

\section{El estudio del cuerpo}

Barnsley en el estudio que hace del cuerpo tiene dos perspectivas. Primero su bajo vientre, como canal semántico del movimiento, y segundo las emociones del bailarín. Ambas posiciones llevan al intérprete a experimentar en la materia y las substancias del cuerpo que llama energías enigmáticas del espíritu o intangibles energías ${ }^{I 2}$, delimitando de este modo el territorio no solo en sus formas visibles (la contracción abdominal), sino lo que motiva esa forma. De allí que su estudio del cuerpo resulte de lo que obtiene de una compleja zona oscilatoria del adentro y el afuera en tanto forma y abstracción del mundo y sus afecciones en la contracción pélvica y su respectiva exhalación. El bajo vientre y las emociones son la síntesis donde se encarnan las imágenes, y a consecuencia de esa transubjetivación de mente y cuerpo la contracción pélvica será el primer símbolo que transfigura los estados psíquicos del bailarín.

Desde las contracciones pélvicas, el cuerpo entra en estado de trance que es internamente el dialogo cuerpo-mente en tanto la contracción reverbera en todo el cuerpo porque como reacción la concatenación de esos signos atravesando el espacio-tiempo, conjugan el movimiento que Barnsley va a precisar como un continuum (acciones). Así, el intérprete patenta su identidad de cuerpo danzante, de personaje escénico, y de intérprete psíquico de la experiencia llevada como danza por nuestra creadora. Subyace en ella, el ideal de oponer a una realidad que se desvanece la idea de una totalidad armoniosa.

El bajo vientre como canal expresivo trasciende la idea de zona orgánica, se vuelve un espacio metafísico donde nos preguntamos, para explicitar mejor esta información, ¿a que expresión ignota se refiere esta contracción pélvica como encarnadora del sentimiento? Los impulsos del movimiento son a priori imágenes energéticas y por lo tanto las acciones físicas desde esta movilización se separan de la posibilidad de ser acciones sentimentalistas porque están desprendidas de las emociones, no están mediadas en esa primera fase por el lenguaje y por ende ningún drama, sino por un accionar orgánico, que parte de una inteligencia kinestésica, un campo de visualización (sentidos orgánicos y propioceptivos); así va descubriendo y dejando fluir la motricidad que va emergiendo como consecuencia de ese impulso de danzar haciendo del cuerpo un activo receptor creativo y no un pasivo instrumento informante, de este modo, la imagen en tanto signo corporal en la escena tiene su pensamiento.

Por otra parte, al anular la posibilidad de intervención de las emociones a priori en la primera posición o instancia en el bajo vientre, esos movimientos corporales o acciones no serán esteticistas, porque el movimiento es genuino en tanto no esta codificado por ninguna técnica dancística; allí radica su posibilidad de ser movimiento dialéctico, oscilatorio. Sus formas pueden contener la expresión más hermosa así como, la más aterradora desde la desvinculación con dos posibles detractores de la experiencia creativa en este campo como son el esteticismo y el sentimentalismo.

12 BARNSLEY, Julie (2013): Op. cit., p. 119. 
Para Barnsley el cuerpo des-codificado convoca según sus palabras a la "gran razón de la naturaleza"13; es la base de su creación. Desde allí, inicia un diálogo de saberes que horizontaliza la experiencia performativa en tanto en la escena otras disciplinas también conforman su obra coreográfica; lo que la ciencia cognitiva llama empatía kinestésica con otras disciplinas. Es decir que Barnsley, en ese plano horizontal de acción en la danza, al dejar al cuerpo desprovisto de sentimentalismo y esteticismo revela la fragilidad de un cuerpo desnudo como la mejor manera en presentar esos impulsos naturales promovidos en sus improvisaciones con nuevas imágenes, a través de posibilidades comunicativas con otros cuerpos desde lo kinestésico y no desde lo conceptual. Por esta razón, el movimiento entre los cuerpos se da de forma corporalmente hablando en la danza como genuina, no hay razón que medie entre el espíritu y su encarnación, o como bien referenciaba Bergson: "Un espíritu con una tendencia natural hacia la materia"14.

En la empatía coreográfica, Barnsley propiciará que otros creadores puedan tener la experiencia del cuerpo en sus prácticas particulares y asimismo ella, la experiencia de otras disciplinas en el cuerpo; siendo esto, su mejor noción de sentido. Lo que se produce en tanto reacción corporal, es la danza del pensamiento desprovisto de conceptos, de lengualingüística; la danza de imágenes en movimiento, como un manifestarse continuo, vital y siempre presente en la memoria del cuerpo.

\section{La empatía kinestésica en Julie Barnsley: un emprendimiento coreográfico diferen- ciado}

En esta perspectiva, sobre el sentido creativo de Barnsley como posibilidad de ampliar la percepción y la consciencia, está exponiendo un cúmulo de significaciones que se producen como efecto. Comenta Deleuze: "El sentido resulta efectivamente producido por esta circulación, como sentido que remite al significante, pero también sentido que remite a lo significado. En una palabra, el sentido es siempre un efecto" ${ }^{15}$. Si bien Deleuze se refiere al sentido del lenguaje, Barnsley lo hace desde el movimiento, siendo este precisamente el código comunicacional en la danza entre emisor-intérprete y receptor-audiencia. Nos propone la posibilidad de entender que en la configuración discursiva de la danza el sentido es un disenso, un vaivén, un movimiento incompleto idóneo de múltiples significados. Por otra parte, encontramos que Deleuze en su libro La imagen-movimiento estudios sobre cine 1, le confiere a los cineastas la categoría de ser pensadores en imágenes. Lo reseña Deleuze: "Hemos pensado que los grandes autores de cine podían ser comparados no sólo con pintores, arquitectos, músicos, sino también con pensadores. Ellos piensan con imágenes-movimiento y con imágenes-tiempo, en lugar de conceptos" ${ }^{16}$. Consideramos que en Barnsley y otros creadores en la danza, ese ha sido precisamente el procedimiento: pensar en imágenes cuando componen con el cuerpo. Conocidos son los solos de Mary Wigman, estimulados por la única imagen de la respiración (Abschied und dank, 1943), o el (Untitled

13 Ibídem., p. 11.

14 BERGSON, Henri (1973): La evolución creadora, (trad. María Luisa Pérez Torres), Espasa Calpe, Madrid, p. 99.

15 DELEUZE, Gilles (2005): Lógica del sentido, (trad. Miguel Morey), Paidós, Buenos Aires, p. 68.

16 DELEUZE, Gilles (1984): La imagen-movimiento. Estudios sobre cine I, (trad. Irene Agoff), Ediciones Paidós, Barcelona-Buenos Aires-México, p. 12. 
Solo 1950) de Merce Cunningham, donde planteaba lo discontinuo del movimiento como una secuencia seriada de imágenes lineales; Appia, utilizando la iluminación no para hacer aparecer o disipar el gesto y el movimiento sino éstos en plena sintonía con la luz; lograba una improvisación de una profundidad real al hacer del brillo y la opacidad en la escena la modulación del espacio-tiempo del gesto, o Lloyd Newson y las investigaciones de DV8 que sobre el cuerpo, la política, el cine y el nuevo teatro verbatim de entrevista y movimiento sitúa a su obra como una oscilación de imagen y movimiento difícil de conceptualizar en tanto son obras más para imaginar. En suma, la afinidad con lo expresado por Deleuze sobre el sentido como efecto, recae en comprender que la encarnación de una imagen en Barnsley la llamaremos gesto.

Como podemos observar, la noción de rebeldía del cuerpo a la que hacemos referencia, corresponde a la determinación anímica y orgánica concentrada en un canal expresivo que toma lugar en el cuerpo (bajo vientre), para encarnar imágenes en la instancia de una contracción; a fin de, que el cuerpo y su resonancia pélvica generen en el más puro acto de creación, el movimiento que enlaza la psique y el cuerpo para transfigurar el lenguaje oculto del alma. Esto supone en Barnsley una empatía kinestésica que necesitamos examinar y que trabaja desde su pensamiento en movimiento, es decir, su semiótica del cuerpo. Barnsley comenta sumando a nuestra reflexión lo siguiente:

En el afán de amplificar las posibilidades perceptivas del cuerpo, a través de su historia Acción Colectiva ha utilizado e incorporado dentro de sus procesos estrategias extraídas de investigaciones corporales provenientes de tendencias dancísticas (convencionales y no convencionales), teatrales, terapéuticas y científicas tanto del Occidente como del Oriente. Impulsamos y creamos prácticas en donde el cuerpo experimenta no solamente estados de armonía, fluidez e integración (tanto espiritualmente como a nivel fisiológico y anatómico) sino también en donde conscientemente rompemos y reordenamos estos estados naturales del cuerpo ${ }^{17}$.

Para Barnsley, la empatía kinestésica es un estado vital y necesario para sustentar la clausura de un sentido movible en su obra coreográfica. Necesidad que agita lo que afecta al pensamiento en tanto lo que contiene como estado prerreflexivo es un impulso intuitivo. A propósito de esa necesidad, Laurence Louppe, dice que para analizar profundamente la danza, debemos apreciarla como la extracción de una sonoridad interior ${ }^{18}$. Pues bien, para nosotros, la materia problemática radica en esa posibilidad de oír esas resonancias silenciosas del adentro y el afuera en la estética dancística de Barnsley en tanto campo de visualización que contiene todos los sentidos promoviendo un equilibrio a su creación entre la diversidad y la particularidad, lo micro y lo macro, entre otros antagonismos que confrontan a la obra como un asunto que se gesta entre piel y piel en los bailarines, otros artistas y sus espectadores kinestésicamente.

Entonces, la agitación de esa sonoridad interior moviliza sui generis combinaciones de lenguajes artísticos, medios y formatos performativos espontáneos y no espontáneos, explorando la interfaz de la globalización, la migración de información de cuerpos y escenas, identidades híbridas y las "nuevas" tecnologías configurando así una estructura coreográfica

17 BARNSLEY, Julie (2013): Op.cit., p. 138.

18 LOUPPE, Laurence (2011): Op.cit., p. 227. 
con formas corporales propias específicas, que emergen, según Barnsley, de ese territorio de la rebeldía del cuerpo en sintonía con la estructura que la contiene. Las comparaciones con estos medios y lenguajes no pretenden posicionar a la danza como una dicotomía entre lo corpóreo-incorpóreo, ni con acontecimientos históricos, sino para adentrarnos en el cuerpo como el espacio central de todas las transformaciones. Lo que implica esa agitación es el meollo de una resonancia oscilatoria entre mundos internos y externos que es su propuesta, que primeramente es orgánica, movible e intuitiva: su nueva sensibilidad.

\section{Conclusiones}

De esta manera, al intentar aproximarnos a una fenomenología de la coreografía desde la perspectiva estética de Barnsley, se evidencia que su poética pondera lo que motiva la danza como acto de cuerpo en tanto contexto e imaginarios encarnados. Ocurre una transubjetivación en sus intérpretes en el continuum de la experimentación por cuanto su propósito lo mantiene en un vilo hasta el final de la obra. Estos propósitos, en esta línea de trabajo al no buscar resultados predefinidos, la sitúan hasta en el no propósito. Repetimos que por sobre todo, importa para esta creadora el proceso en riesgo: el recorrido. Es decir, que parte de su secreto es revelado en la medida que el cuerpo se rebela con lo predeterminado, haciendo de la danza la cristalización de su interés coreográfico. Esto supone aciertos y desaciertos en la creación porque el recorrido es transversal y no lineal, nos interesa lo que contiene de riesgo por donde hemos recorrido parte de esa fenomenología.

Una semántica de la rebeldía del cuerpo, es quizás el lenguaje abstracto que configura la posibilidad más próxima en vivir la danza como una experiencia de incertidumbre, es decir, que Barnsley construye un estado de alerta examinando las pulsaciones inmediatas previas al movimiento; por el cual, éste expresa esa concreción de imaginario como signos, por ende, gestos y que bien ha focalizado en el bajo vientre. Esa pre-movilidad, es casi sincrónica al presente inmediato del fluir de la danza, la acompaña silenciosamente, y ese posible nuevo razonamiento sobre ese estado en esa parte del cuerpo sucede en la medida que se difuminan los límites de la creación con el cuerpo, incentivando desde, las experiencias personales, los saberes, la memoria afectiva, las emociones y descodificando lo que la misma historia ha patentado como formula de repetición gestual. Las metáforas barnsleynianas como resonadores de la pelvis son intentos de representar percepciones o visiones que superan los límites de la poética realista en favor de una nueva poética que remonta lo inexpresable en términos lógicos. Este aspecto estaría directamente relacionado con la proposición que Alazraki19 atribuye a Nietzsche de "reemplazar el intelecto por la intuición, la razón por el mito, los conceptos por las metáforas, la ciencia como ruta hacia el mundo exterior por el arte como un puente hacia la verdadera realidad", es decir, si parafraseamos la cita anterior; Barnsley propone la aprehensión del mundo mediante una poética de la danza que atiende a los estímulos de la cotidianidad. Con esto, su discurso, alejado del esteticismo, recupera una fuente vital como es el acontecimiento del día a día como impulso creativo y que bien a codificado en el bajo vientre. En esto Barnsley va a atender aquella dádiva de Artaud que

19 ALAZRAKI, Jaime (1983): En busca del unicornio: los cuentos de Julio Cortázar: elementos para una poética de lo neofantástico, Gredos, Madrid, p. 54. 
decía: "no es en la escena donde hay que buscar hoy la verdad sino en la calle"20. De cara a un futuro incierto, el cuerpo en estado de rebeldía nos deja como receptores de ese mundo de imágenes en movimiento, como seres entreabiertos.

Ahora bien, la rebeldía del cuerpo entendida como una interpretación de acciones es otra cosa a nuestro entender; no la debemos comprender como un acto inconsciente, porque toda acción no prescinde de su relato que, en pocas palabras, para Barnsley es la búsqueda de un porqué o la espera por encontrar algo y además interpretar las acciones implica establecer un análisis con la danza misma en tanto imaginario. Entonces el relato permanecerá en Barnsley como una búsqueda y la acción en esa búsqueda es el cuerpo rebelde porque las acciones en el bailarín son explosiones efímeras de vida, son excesos que desaparecen en el tiempo definido de su representación, por ello, rebeldía debe ser irrupción de esas acciones sobre las historias, sobre la posibilidad de violentarlas para transformarlas y eso implicará para Barnsley, en el mejor territorio hermenéutico, una interpretación primero de la vida y luego de la danza. Pero más allá de esa interpretación, interesa también la manera como ella ha jerarquizado ese mundo de interpretaciones en su proceso de interpretación mayor llamado Acción Colectiva: un proyecto que se insertó en una Venezuela de conflictos políticos y sociales.

\section{Bibliografía}

Alazraki, Jaime (1983): En busca del unicornio: los cuentos de Julio Cortázar: elementos para una poética de lo neofantástico, Gredos, Madrid.

Artaud, Antonin (1964): El teatro y su doble, Editorial Sudamericana, Buenos Aires.

Barnsley, Julie (2013): El cuerpo como territorio de la rebeldía, 2a. ed., UNEARTE, Caracas.

Bergson, Henri (1973): La evolución creadora, (trad. María Luisa Pérez Torres), Espasa Calpe, Madrid.

Cornago, Óscar (2003): Pensar la teatralidad. Miguel Romero Esteo y las estéticas de la modernidad, Editorial Fundamentos, Madrid

Deleuze, Gilles (1984): La imagen-movimiento. Estudios sobre cine I, (trad. Irene Agoff), Ediciones Paidós, Barcelona-Buenos Aires-México.

Deleuze, Gilles (2005): Lógica del sentido, (trad. Miguel Morey), Paidós, Buenos Aires.

Eco, Umberto (1998): Signos, (trad. Francisco Serra), Editorial Labor, Barcelona

Finol, José Enrique (2015): La corpoesfera. Antropo-semiótica de las cartografías del cuerpo, Ediciones CIESPAL, Quito, p. 41

Fischer-Lichte, Erika (2011): Estética de lo performativo, (trads. Diana González Martín; David Martínez Perucha), Abada Editores, Madrid.

Louppe, Laurence (2011): Poética de la danza contemporánea, (trad. A. Fernández), Ediciones Universidad de Salamanca, Salamanca.

Molinuevo, José Luis (2015): Laocoonte, "Definición, uso, abuso y propuestas estéticas". Revista de Estética y Teoría de las Artes. Vol 2. VOL. No 2. España

Turner, Victor (1982): From Ritual to Theatre. The human seriousness of play, Performing Arts Journal Publications, New York.

20 ARTAUD, Antonin (1964): El teatro y su doble, Editorial Sudamericana, Buenos Aires, p. 79. 
